\title{
Variety Check as an Element of Precision Farming in the Modern Agriculture
}

\author{
Anna Lyubimova \\ Fodder Grain Selection Laboratory \\ Federal State Budgetary Educational \\ Institution of Higher Education \\ «Northern Trans-Ural State Agricultural University» \\ Tyumen, Russia \\ ostapenkoav88@yandex.ru
}

\author{
Dmitry Eremin \\ Department of Soil Science and Agrochemistry, Federal \\ State Budgetary Educational \\ Institution of Higher Education \\ «Northern Trans-Ural State Agricultural University» \\ Tyumen, Russia \\ soil-tyumen@yandex.ru
}

\begin{abstract}
Maintaining constant biotypical composition of cultivars and control of their varietal purity are the mandatory requirements for achieving stable high yields of crops. Method of prolamin electrophoresis has been successfully applied for the varietal purity control of batches of original and reproduction seeds. Oat is a promising crop for growing in Western Siberia. This research aimed at development of reference spectra of oat varieties for use in a laboratory-based variety check. The material of the study was represented with caryopses from 223 samples of the common oat of various environmental and geographic genesis. It has been established, that $47.7 \%$ of the samples are homogeneous in the component composition of avenin. Heterogeneous samples included from 2 to 9 biotypes. The most common for the locus Avn A was the unit component variant A2 (41.1\%); for the locus Avn B - B1 (25.6\%), B4 (16.1\%); for the locus Avn C - C3 (26.0\%) and C2 (17.9\%). Genetic formulas of varieties cultivated in Tyumen oblast are: var. Perona Avn A4 B4 C2, var. Talisman Avn A4 B4 C2, var. Foma Avn A4 B5 C1, var. Tyumen hull-less Avn A2 Bned C3, var. Megion Avn A2+ned Bned C5, var. Otrada Avn Aned+4B4C1. The obtained reference spectra and the genetic formulas of avenin were used for creation of variety sheets for the analyzed varieties; subsequently these sheets were added to the database of the Laboratory of Cultivar Seed Identification to allow efficient laboratory-based monitoring of varieties and purity of seed batches at any stage of their production and sales.
\end{abstract}

Keywords- oat, electrophoresis, avenin, reference spectrum, varietal purity.

\section{INTRODUCTION}

Improvement of selection and seed production, application of high-quality seeds for growing and maintaining the constant biotype composition of varieties and their varietal purity are very important for increase in crop production. The most common methods of determining varietal attributes of seeds in Russia are field evaluation and field approval; both are based on morphological characteristics. However, these methods have a number of disadvantages. Currently, one farm may cultivate several cultivars of the same crop. When the same machinery is used for sowing, harvesting and enhancement of grain, mechanical mixing of various cultivars is almost inevitable. Taking into account that many modern cultivars pertain to the same subvariety, visual identification of cultivar admixture becomes rather problematic. Besides, more and more modern cultivars are complex populations. Maintaining these cultivars during seed production is harder, as their component biotypes while having different biological properties may have very little morphological differences. Due to that, application of new methods based on genetics and physiology finds ever-wider application in seed production $[1$, $2,3]$. The most successful method used for laboratory-based monitoring of varietal purity and conformance of original and reproduction seeds is electrophoresis of alcohol-soluble storage proteins of seeds - prolamins [4, 5, 6]. Due to a significant polymoprhism of molecular mass and the number of components, each variety or biotype has its own specific component composition of prolamins $[7,8,9]$.

Determination of variety conformance and detection of admixtures is based on comparison of obtained electrophoretic spectra of the variety under studies with its reference spectrum.

Oat is one of the main crops planted in Western Siberia. Oat farming in this region offers great opportunities and has large practical importance due to its capability to grow and give stable high yields under a wide range of natural and environmental conditions. In recent years, interest in this crop has grown exponentially, as almost all wheat grown in TransUral is used for food, while provision of stable fodder base requires growing fodder grain crops. Storage proteins (avenins) have been successfully used for analysis of genetic diversity.

Studies of genetic control and characteristic of inheritance of components of the electrophoretic spectra of oat prolamine have shown that they are inherited groupwise and are controlled by three independent loci: Avn A, Avn B, Avn C [10]. High level of polymorphism of oat storage proteins make it possible to identify genotypes of various varieties and reveal intra-variety heterogeneity.

Research objective: development of reference spectra of oat varieties for use in the laboratory-based variety check. 


\section{SUBJECTS AND METHODS}

The research has been conducted in the Laboratory of Cultivar Seeds Identification in the Agrobiotechnological Center of the Northern Trans-Ural State Agricultural University.

The material of the study was represented with caryopses from 223 samples of the common oat of various environmental and geographic genesis. Seeds for the research have been provided by R\&D Institute of Agricultural Research of the Northern TransUrals, a branch of Tyumen Scientific Center of the Siberian branch of the Russian Academy of Sciences and by the Federal Research Center of the AllRussian Institute of Plant Genetic Resources named after N.I. Vavilov (VIR).

The analysis used 100 randomly selected caryopses of each species. One-dimensional electrophoresis of the oat storage proteins followed the standard method given in [11], with some modifications [12]. From each sample, 100 seeds were randomly chosen for the analysis. The proteins were extracted from the flour of various individual caryopses by adding $90 \mu \mathrm{l}$ of $70 \%$ ethanol with subsequent incubation at $40{ }^{\circ} \mathrm{C}$ for 40 minutes. The obtained extract was centrifuged for 4 minutes at $10,000 \mathrm{rpm}$. The supernatant then was moved to new Eppendorf test tubes, $300 \mu \mathrm{l}$ of methylene green coloring solution was added ( $60 \mathrm{~g}$ of sucrose, $0.1 \mathrm{~g}$ of methylene green, $100 \mathrm{~g}$ of carbamide and $100 \mathrm{ml}$ of aluminum-lactate buffer). Protein extract $(23 \mu \mathrm{l})$ was put in polyacrylamide gel and separated by electrophoresis. The polyacrylamide gel contained: $13.17 \mathrm{~g}$ of acrylamide, $0.66 \mathrm{~g}$ of N,N'methylenebisacrylamide, $7.17 \mathrm{~g}$ of carbamide, $2 \mathrm{mg}$ of $\mathrm{Fe} 2(\mathrm{SO} 4) 3 \times 9 \mathrm{H} 2 \mathrm{O}, 80 \mathrm{mg}$ of ascorbic asid and $0.26 \mathrm{~g}$ of aluminum lactate. All the reagents were dissolved in $100 \mathrm{mg}$ of aluminum-lactate buffer. For polymerization, $25 \mu$ of $15 \%$ hydrogen peroxide were added to $100 \mathrm{ml}$ of gel solution. For electrophoresis, VE-20 chambers were used, manufactured by Helicon, Russia, which formed the plates sized $178 \times 175 \times 1.5$ $\mathrm{mm}$. The electrophoresis was conducted at a constant voltage of 500V during 3.5-4.0 hours. Fixation and coloring of the gel plates were performed in the $10 \%$ solution of trichloracetic acid with addition of $0.05 \%$ coomassie brilliant blue R-250 in ethanol and lasted for 8 hours. Identification of allelic variants of the component units controlled by avenin-coding loci was conducted based on a catalog developed by V.A. Portyanko and colleagues. [10] (Fig.1).

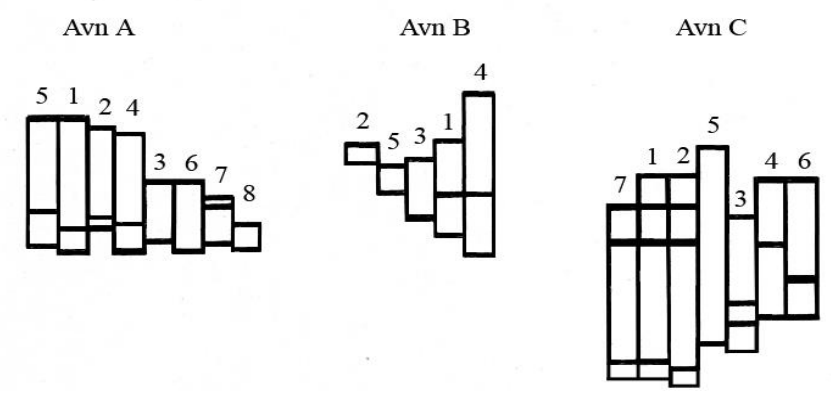

Fig. 1- Catalog of allelic variants in component units of avenin electrophoretic spectrum, controlled by loci Avn A, Avn B, Avn C. (Portyanko et al., 1987)
Electorphoregrams of the spectra were recorded as genetic formulas. For that end, a string was formed starting with Avn, and then a letter, signifying the corresponding locus (A, B and C) and a sequential number of an allelic variant of the prolamin component unit that is controlled with the locus. In case of heterogenic samples having more than one allele in one or several prolamin-coding loci, the allelic variants are specified with the «+» sign between them. If a component unit identified is absent in the catalog, "ned" marker is put instead of its number into the genetic formula. Caryopses of common oat cultivar Astor (Avn A2 B4 C2) were used as a standard.

\section{RESULTS}

It has been established, that $47.7 \%$ of the samples are homogeneous in the component composition of avenin. Heterogeneous samples included from 2 to 9 biotypes. The number of protein components in the spectra varied from 5 to 11. For the analyzed samples, the avenin component units were identified that are controlled with the prolamin-coding loci. It has been established, that the most common variant in the locus Avn A is the unit component variant A2 (41.1\%). Units A1 and A4 were found in spectra of 8.1 and $7.1 \%$ of samples, respectively. The frequency of the rest of alleles of this locus was between 0.5 and $2.5 \%$ each. For the locus Avn $\mathrm{B}$, the highest frequency was observed for the component units B1 (25.6\%) and B4 (16.1\%); for the locus Avn C they were C3 $(26.0 \%)$ and C2 $(17.9 \%)$. Differences in the observed frequency of the avenin unit components may be caused by the gene clusters that control synthesis of variants A2, B1, $\mathrm{B} 4, \mathrm{C} 3, \mathrm{C} 2$ and $\mathrm{C} 1$ being tangled with gene associations that carry adaptively or agriculturally-valuable features giving advantages to the carrier species. During the selection work, genotypes with these gene associations are selected for, thus, the frequency of their marking alleles increases.

As a result of identifying the prolamin component units, genetic formulas of avenin were composed for each sample. Due to the high level of storage protein polymorphism, such formulas are cultivar-specific and virtually unique. Knowledge of the genetic formulas of the samples make it possible to use the collection more efficiently, including maintaining the constant biotypical composition of the collected samples and facilitates optimal selection of parent forms for crossing.

An oat varieties data base has been developed by the authors to systematize the research results. Each sheet included information covering a separate sample, including VIR catalog number, cultivar name, genesis, data on the number of biotypes and their ratio, genetic formula describing allelic state of the loci Avn A, Avn B, Avn C and an image of the reference electrophoretic spectrum.

The sheets stored in the database are used as references for identification of varieties, hybrids, lines and clones. However, this information is especially important for assessment of varietal conformance and varietal purity of oat cultivars included in the State Register of Selection Achievements. In the territory of Tyumen oblast, 6 varieties of the common oat are cultivated: Perona, Megion, Tyumen hull-less, Talisman, Otrada, Foma. 
The analysis of these cultivars has shown that Peron, Talisman, Tyumen hull-less and Foma are homogeneous in avenin component composition. Heterogeneous varieties Megion and Otrada are represented by two variants of avenin spectra in a 2:1 ration. Heterogeneity of the cultivars is explained by peculiarities of their development. The number of biotypes in a cultivar depends on the number of prolamincoding loci for which the heterozygous parent plant was selected from hybrid populations.

For the analyzed cultivars, variants of prolamin units were identified, controlled by the loci Avn A, Avn B, Avn C. The genetic formulas of the cultivars have the following forms: Perona Avn A4 B4 C2, Talisman Avn A4 B4 C2, Foma Avn A4 B5 C1, Tyumen hull-less Avn A2 Bned C3, Megion Avn A2+ned Bned C5, Otrada Avn Aned+4B4C1.

Prolamin spectra of Perona and Talisman cultivars are identical, their genetic formulas are the same and have the form of Avn A4 B4 C2. Identity of the prolamin spectra may be a result of a common genesis of the cultivars, as well as that of selection of genotypes with such gene associations, which correspond to certain variants of avenin unit components. However, Peron and Talisman cultivars were developed in different countries and have no common parents. Another reason for the sameness of the spectra is a mechanical contamination of one cultivar with seed material of another. In this case, the risk of mechanical contamination is especially high, taking into account that there is no primary seed development of the Peron cultivar currently.

In case of the sameness of the prolamin electrophoretic spectra, differences between the cultivars may be revealed by using other genetically polymorphic marker systems [13, 14]. However, when assessing varietal conformance and varietal purity of seeds of Perona and Talisman cultivars, it should be taken into account, that these cultivars are indistinguishable to the electrophoresis of alcohol-soluble storage protein. Thus, these cultivars require especially thorough seed development work to prevent mechanical or biological contamination of one cultivar with the seed material of another.

From the obtained reference spectra and genetic formulas of avenin, sheets were created for the common oat cultivars included in the State Registry of Selection Achievements in Tyumen oblast (Fig. 2) and subsequently added to the laboratory database.
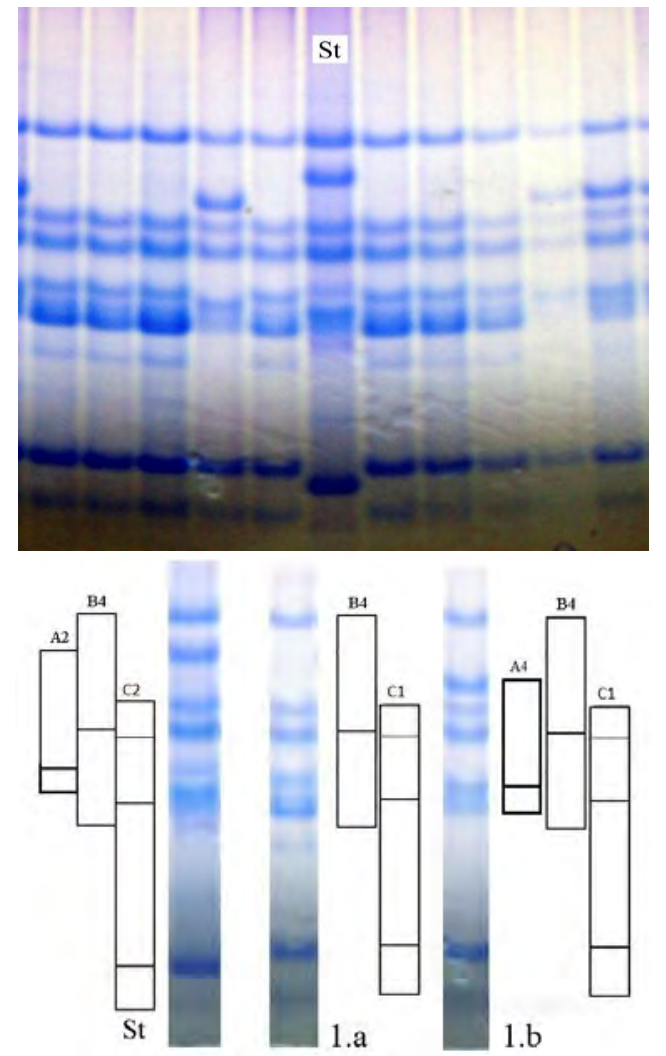

B

Fig. 2- Variety sheet of Otrada cultivar of the common oat. A) reference spectrum; B) -diagrams of avenin unit components 1.a the first biotype, $1 . \mathrm{b}$ - the second biotype. St - Astor (standard).

The obtained reference spectra of oat cultivars storage proteins are used in the Laboratory of Cultivar Seed Identification of the Northern Trans-Ural State Agricultural University for assessment of varietal conformance and varietal purity of elite and reproduction seeds batches.

Conformance of the analyzed cultivar to the declared one is established by visual comparison of the caryopses spectra between the studies cultivar and the reference spectra. As an example, let us give the results of the laboratory analysis of a seed batch that in its support documentation was declared as being common oat, Otrada cultivar. According to the reference spectrum, this cultivar is heterogeneous by its avenin component composition and consists of two biotypes. During the analysis of storage proteins of the sample, it has been established that some of the caryopses have a spectrum different from that of the Otrada cultivar (Fig. 3). Another part of the spectra conformed to the reference spectrum of the Otrada cultivar. 


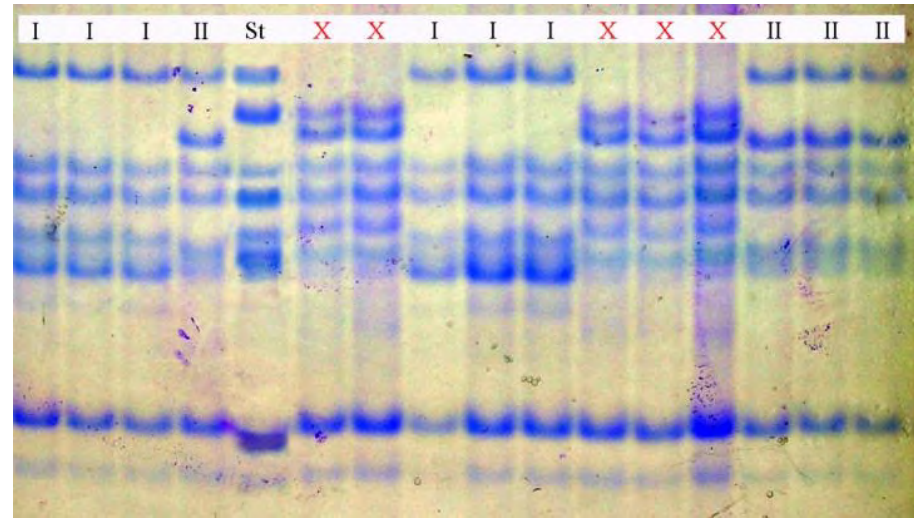

Fig. 3- Electrophoretic spectra of the Otrada cultivar storage proteins (I - firs biotype, II - second biotype) and cultivar contamination (tracks marked with a cross). St - Astor (standard).

Thus, as a result of laboratory evaluation of varietal conformance and varietal purity, it has been established, that the studied sample corresponds to the Otrada cultivar, however it also includes the mechanical contamination from another cultivar seed material.

\section{CONCLUSION}

Electrophoretic analysis of grain prolamins may be successfully applied at all the stages of selection process, from search for source material to registration of the developed cultivars, strain test, seed development and production quality control. The database of reference spectra as created in the Northern Trans-Ural State Agricultural University and covering the cultivars being cultivated in Tyumen oblast, will allow for efficient laboratory monitoring of varietal belonging and purity of seed batches at any stage of its production and sales. Oat cultivars Perona and Talisman are identical in their prolamin spectra and require an especially thorough seed development in case of cultivation at the same farm to avoid biological or mechanical contamination of one culitvar with the seed material of another.

To monitor varietal purity and conformance of original and reproduction seeds of grain crops, as well as for timely discovery of procedural violations, it is necessary to regularly conduct laboratory-based control of the varietal properties of seed by the prolamin electrophoresis method.

\section{Acknowledgment}

The research has been conducted under the government order (Research priority X.10.4 Program X.10.4.150 Project X.10.4.150).

\section{References}

[1] D. Hailegiorgis, Ch.A. Lee, and S.J. Yun, "Allelic variation at the gliadin coding loci of improved Ethiopian durum wheat varieties", J. Crop Sci. Biotech., vol. 20 (4), pp. 287-293, December 2017. DOI: 10.1007/s12892-017-0106-0.

[2] T. Gagkaeva, O. Gavrilova, A. Orina, and I.G Loscutov, "Diversity of Avena Species by Morphological Traits and Resistance to Fusarium Head Blight", Russian Journal of genetics: Applied Research., vol. 8 (1), pp. 44-51, January 2018. DOI: 10.1134/S2079059718010070.

[3] M.M. Zlotina, O.N Kovaleva, I.G Loskutov, and E. Potokina, "The use of allele-specific markers of the Ppd and Vrn genes for predicting growing-season duration in barley cultivars", Russian Journal of genetics: Applied Research., vol. 3 (4), pp. 50-61, July 2013. DOI: 10.1134/S2079059713040114

[4] A. Lyubimova and D. Eremin, "Laboratory varietal control as a guarantee of successful work of gribusiness in Russia", [MATEC Web of Conferences, 170, pp. 04015, 2018]. https://doi.org/10.1051/matecconf/201817004015

[5] M. Utebauev, S. Dashkevich, A. Babkenov et al., "Application of gliadin polymorphism for pedigree analysis in common wheat (Triticum aestivum L.) from Northern Kazakhstan", Acta Physiologiae Plantarum., 38:204, August 2016. https://ink.springer.com/article/10.1007/s11738016-2209-4

[6] S. Doneva, N. Daskalova, and P. Spetsov, "Transfer of novel storage proteins from a synthetic hexaploid line into bread wheat", ZemdirbysteAgriculture, Vol. 105:2, 2018, pp. 113. DOI: $10.13080 / z-$ a.2018.105.015

[7] A. Kudryavtsev, V. Dedova, V. Melnik, A. Shishkina, "Genetic diversity of modern russian durum wheat cultivars at the gliadin-coding loci", Russian journal of genetics, vol. 50, nn 5, pp. 483-488. 2014. DOI: $10.1134 / \mathrm{S} 1022795414050093$

[8] E.V. Lyalina, S.V. Boldyrev and A.A. Pomortsev, "Current state of the genetic polymorphism in spring barley (Hordeum vulgare L.) from Russia assessed by the alleles of hordein-coding loci," Russian Journal of Genetics, Vol. 52, no 6, P. 565, 2016. DOI: $10.1134 / \mathrm{S} 1022795416060077$

[9] L.V. Obukhova and V.K. Shumny, "The inheritance of endosperm storage proteins by the line of the Saratovskaya 29 cultivar of common wheat from its parental forms", Russian Journal of Genetics, vol. 52, no. 1, P. 49, 2016. DOI: 10.1134/S1022795416010117.

[10] V.A. Portyanko, A.A. Pomortsev, N.A. Kalashnik, V.I. Bogachkov, A.A. Sozinov, "The genetic control of avenins and the principles of classification," Russian Journal of Genetics, vol.23, no 5. pp. 845-853, 1987.

[11] ISO 8981 (1993) Wheat-identification of varieties by electrophoresis http://www.iso.org/iso/catalogue_detail.htm?csnumber=16506

[12] A.A. Pomortsev, A.M. Kudryavtsev, V.P. Upelniek, V.G. Konarev et al. Method of conducting laboratory variety control for groups of agricultural plants, 2004, 96 p. [in Russian].

[13] L.V. Obukhova, L.I. Laikova, and V.K. Shumny, "Analysis of storage proteins (prolamines, puroindolines and Waxy) in common whea lines [Triticum aestivum L. × (Triticum timopheevii Zhuk. $\times$ Triticum tauschii)] with complex resistance to fungal infections," Russian Journal of Genetics, vol.46, no 6, pp. 672-676, 2010. https://link.springer.com/article/10.1134\%2FS1022795410060062.

[14] N.K. Singh, K.W. Shepherd, and G.B. Cornish, "A simplified SDSPAGE procedure for separating LMW subunits of glutelin," Journal of Cereal Science, vol. 14, pp. 203-208, Nowember 1991. https://doi.org/10.1016/S0733-5210(09)80039-8 